\title{
Environmental Impacts of Biomass Energy Sources in Rwanda
}

\author{
Eustache Hakizimana $^{1, *}$, U. G. Wali ${ }^{1}$, Diego Sandoval ${ }^{2}$, Kayibanda Venant ${ }^{3}$ \\ ${ }^{1}$ African Center of Excellence in Energy for Sustainable Development, University of Rwanda, Rwanda \\ ${ }^{2}$ Department of Civil, Environmental and Geomatics Engineering, University of Rwanda, Rwanda \\ ${ }^{3}$ Department of Mechanical and Energy Engineering, University of Rwanda, Rwanda
}

Received July 9, 2020; Revised August 31, 2020; Accepted September 11, 2020

\section{Cite This Paper in the following Citation Styles}

(a): [1] Eustache Hakizimana, U. G. Wali, Diego Sandoval, Kayibanda Venant, "Environmental Impacts of Biomass Energy Sources in Rwanda," Energy and Environmental Engineering, Vol. 7, No. 3, pp. 62 - 71, 2020. DOI: 10.13189/eee.2020.070302.

(b): Eustache Hakizimana, U. G. Wali, Diego Sandoval, Kayibanda Venant (2020). Environmental Impacts of Biomass Energy Sources in Rwanda. Energy and Environmental Engineering, 7(3), 62 - 71. DOI: 10.13189/eee.2020.070302.

Copyright $\bigcirc 2020$ by authors, all rights reserved. Authors agree that this article remains permanently open access under the terms of the Creative Commons Attribution License 4.0 International License

\begin{abstract}
Rwanda is adopting a new concept of using an alternative energy source as a cooking fuel, where more than the majority of the population live in a rural area and use wood for all heating needs. Biomass in the form of firewood and charcoal plays a significant part in Rwanda's economy. This accounted for 83 per cent of Rwanda's energy consumption in 2020. Biomass technology can be converted into fuel through some different processes, including solid fuel combustion, digestion, pyrolysis, fermentation and catalyzed reactions. With the government engaging in improving the health and protection of the environment, it becomes mandatory to look for alternative fuels not harmful or way to improve the methodology and the quality of stoves used in the country. In this study, the impacts of using biomass energy were assessed and mitigation measures were also proposed. The result shows that reducing reliance on unsustainable use of wood fuel and adds ongoing efforts in Rwanda to transition from the traditional use of biomass to Liquefied Petroleum Gas (LPG) or other improved cooking technology for fuel in a sustainable way. Along with this, the use of biomass for fuel is having harmful effects through health impacts and emissions. The article fills an important gap on the energy literature on Rwanda, as it gives detailed info on the cooking sector.
\end{abstract}

Keywords Biomass Energy, Impacts Assessment, Cooking Fuels, Improved Stoves

\section{Introduction}

Rwanda relies on fuelwood for heating and cooking. Fuelwood in Rwanda accounts for at least 80.4 percent of energy consumption and as a result, there is significant deforestation across the country. Furthermore, population growth is intensifying deforestation and causing more environmental degradation. For this reason, in 2020 the government of Rwanda through the Ministry of Land and forestry has begun a campaign to reduce the use of firewood for cooking while promoting other technologies such as gas and energy saving stoves to limit deforestation.

The campaign will include the planting of more trees that will be catered for before being felled to ensure they mature. Rwanda launched a national forest planting season 2017/2018, in which more than 45,000 hectares of agroforests will be planted especially in eastern Rwanda. According to the ministry, current country forests cover stands at 704,997 hectares, equivalent to 29.6 percent, of which planted forests constitute 17.7 percent and 11.9 percent are natural forests [1]. The biomass is used in the form of firewood, charcoal and agricultural residues which is mainly used in cooking both in rural and urban populations as well as some industries. Biomass consumption is putting pressure on existing resources, with an estimated 870,000 tons of woody biomass deficit in 2009. Rwanda heavily relies on traditional biomass, for instance, wood, charcoal, dung, with more than 83 percent of households using firewood and demand for biomass energy continues to be a major driver of deforestation. An 
increase in demand for cooking fuel has exerted immense pressure on forestry resource and the country aims to reach a potential net reduction in wood used to 5770000 tons by 2030. Rwandans still rely on biomass in big percentages and the government of Rwanda needs an investor who is capable of replacing firewood-the traditional cooking energy which is putting the country forests under pressure. Rwanda's energy balance shows that about 85percent of its overall primary energy consumption is based on biomass ( $99 \%$ of all households use biomass for cooking). 11\% from petroleum products (transport, electricity generation and industrial use) and $4 \%$ from hydro sources for electricity as shown in figure 1 .

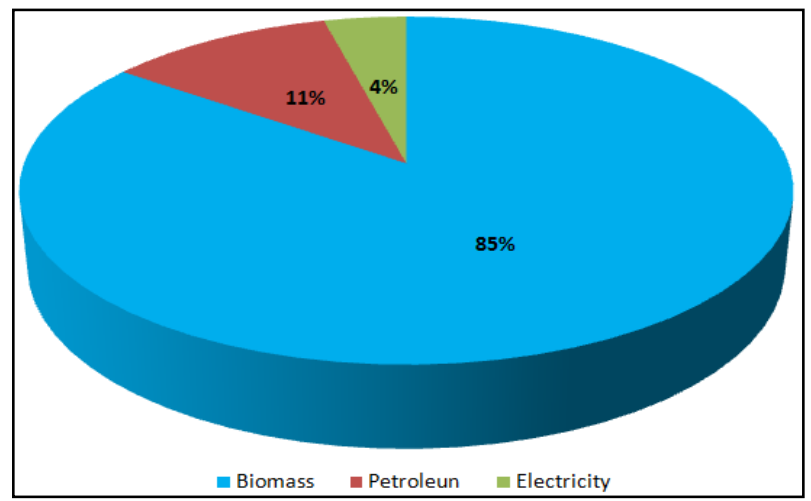

Figure 1. Total primary energy consumptions in Rwanda

\section{Rwanda Energy Sector Structure}

The mission of the Rwanda energy sector is to create conditions for the provision of safe, reliable, efficient, cost-effective and environmentally appropriate energy services to households and all economic sectors on a sustainable basis. The management of energy systems in Rwanda involves various ministries and government agencies as well as private entities and individuals. The main parties involved in the energy in the country include the Ministry of Infrastructure (MININFRA), genuinely interested in biomass issues, but it is mainly concerned with end-users aspects and energy conversion, transformation and efficiency; the Ministry of Natural Resources (MINIRENA), focuses on the silvicultural aspects and productivity of plantations, and Ministry of Agriculture and Animal Resources (MINAGRI) on the agroforestry aspects of biomass. Other Ministries such as the Ministry of Finance and Economic Planning (MINECOFIN), the Ministry of Local Government (MINALOC), the Ministry of Trade and Industry (MINICOM) have an interest in part of the technical and regulatory aspects of the biomass supply and use chain. MININFRA is responsible for the development of national policies and strategies related to energy generation in the country, while regulation of the sector is the preserve of the Rwanda Utilities Regulatory Authority (RURA). Rwanda Energy Group (REG) is a private company established in
2014, wholly owned by the government. It carries operations out by two subsidiaries, the Energy Development Corporation Limited (EDCL) and the Energy Utility Corporation Limited (EUCL).

The EDCL is responsible for developing both generation and transmission projects, exploiting new energy resources, and executing a least-cost power development plan and with Independent Power Producers (IPPs) [18]. While the EUCL is in charge of day to day operations of power generation, transmission, distribution and sales to final customers. The utility will also play a key role in the execution of power purchase/sales agreements with IPPS and other regional utilities for import and export. The institutional framework of the energy sector in Rwanda is shown in figure 2 .

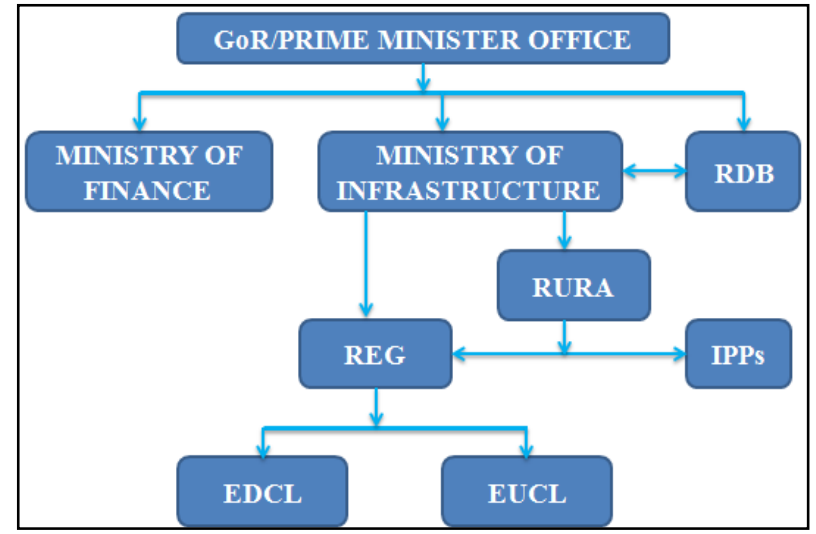

Figure 2. The institutional framework of the energy sector

\section{Current Status of Biomass Energy in Rwanda}

The analysis of supply and demand of energy in Rwanda indicates that today approximately 83 percent of primary energy still comes from biomass, in the form of wood that is used directly as a fuel or is converted into charcoal, together with smaller amounts of agricultural waste. Biomass is largely consumed for cooking, with wood used by rural households and charcoal by urban households. This leaves serious negative impacts on forests, environmental degradation and people's health, which makes the government determined to cut the use of firewood for cooking by institutions such as hotels, schools, hospitals, prisons, police and the army. The government of Rwanda has embarked on strategies aimed to reduce its dependence on biomass as a source of energy by 2024 . The current national energy consumption is shown in figure 1. Firewood is the most common cooking fuel in Rwanda and it is used in various types of woodstoves, $93 \%$ of rural households utilize firewood as it is considered in most cases still freely available [4]. More than half of the firewood stoves operating nationwide are three stones stoves as shown in figure 4 . Approximately $65 \%$ of households living in major urban areas like Kigali, Huye 
and Rwamagana use charcoal to meet most of their cooking needs, through both traditional and improved cookstoves. Most of the charcoals are produced locally, in urban areas, charcoal is the most preferred fuel due to its long-life storage and low-cost transportation as it is smaller in volume and weight and has higher heat content compared to firewood [5].

In Rwanda, most charcoal $(86 \%)$ is produced in a rather inefficient way and by use of traditional earth mound kilns with the average thermal efficiency of about $12 \%$ (air dry $\mathrm{kg}$ of charcoal/air dry $\mathrm{kg}$ of wood) [6]. Agricultural residues used to constitute only a small percentage of fuels used by the households but their use has increased year after year as a substitute due to wood scarcity, particularly among the poorest households of rural semi-arid areas. In Rwanda, the most used agricultural residues at the household level are cereals (maize, sorghum, stalks and rachis), wheat and rice straws and husks, tubes like cassava stalks, banana leaves, coffee husks, vegetable wastes (beans, groundnuts, soya, coffee pulps and dried caw dung). A rice husk is used as a fuel mainly for brick firing in the major rice growing areas. Sugar bagasse, coffee husks, rice husks and wheat husks are also used in brick making industries. In urban areas, poor households use sawdust and other end-cuts from wood processing industries without using appropriate cookstoves [5].

The exposure to polluting cooking energy is different between rural and urban areas. We observe a slow but increasing use of clean energy in the metropolitan area where we record $2 \%$ of the usage of LPG cooking gas and $63.9 \%$ of households using an improved stove, while in a rural area only $22.4 \%$ household's use an improved oven, and use of clean fuel stoves is negligible [16]. The transition from Tier 0 to Tier 5 will take time and will pass by intermediate cooking fuels and improved stoves on Tier 3 and 4 before reaching Tier 5 , as presented in table 1 .

Based on a review of recent data, five key market segments as shown in table 2 have been defined for biomass energy used for cooking, heating and drying processes in Rwanda: Household sector (Rural and Urban), commercial food industry, public institutions and processing and production sectors. The use of firewood by rural households is an attractive option as it is freely available to most households. In urban areas, charcoal is the preferred fuel. This is due to its long-life storage and relatively low-cost transportation, given its smaller volume and weight compared to firewood. The classification of biomass energy sources is shown in figure 3 .

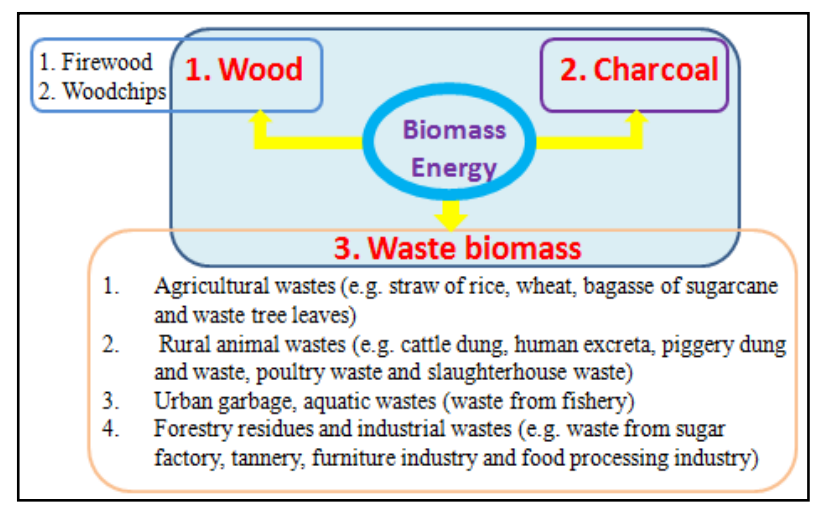

Figure 3. The classic biomass energy

Table 1. Cooking with different fuels and stove emission tier [16]

\begin{tabular}{|l|l|c|}
\hline Type of fuel & Description of level & Tier \\
\hline \multirow{5}{*}{ Firewood, dung, twigs, and leaves } & Three-stone, tripod, flat mud ring & 0 \\
\cline { 2 - 3 } & Conventional improved cookstove & 1 \\
\cline { 2 - 3 } & Improved cookstove with chimney, rocket stove with conventional material for insulation & 2 \\
\cline { 2 - 3 } & Rocket stove with high insulation, rocket stove with chimney (not well sealed) & 3 \\
\cline { 2 - 3 } Charcoal & Rocket stove with chimney (well sealed), rocket stove gasifier, batch feed gasifier & 4 \\
\hline & Traditional charcoal stoves & 0 \\
\cline { 2 - 3 } & Old generation improved cookstoves & 2 \\
\cline { 2 - 3 } & Conventional improved cookstoves & 3 \\
\cline { 2 - 3 } & Advanced insulation charcoal stoves & 4 \\
\cline { 2 - 3 } & Advanced secondary charcoal stoves & 3 \\
\hline \multirow{3}{*}{ Rice husks, pellets, and briquettes } & Natural draft gasifier (only pellets and briquettes) & 4 \\
\cline { 2 - 3 } & Forced air & 5 \\
\hline LPG, biogas and Electricity & & \\
\hline
\end{tabular}

Table 2. Main biomass market segments

\begin{tabular}{|l|l|}
\hline Segment & User Types \\
\hline Rural households & Rural consumers who rely mostly on firewood for cooking and heating purposes \\
\hline Urban Households & Urban consumers who rely heavily on charcoal for cooking and heating purposes \\
\hline Commercial food industry & Hotels, bakeries and restaurants who rely on charcoal and firewood for cooking \\
\hline Public institutions & Schools, prisons, military, refugee camps relying on charcoal and firewood for cooking purposed \\
\hline $\begin{array}{l}\text { Processing and production } \\
\text { sector }\end{array}$ & Tea factories utilize firewood for tea curing and brick making processes utilize firewood for brick making. \\
\hline
\end{tabular}




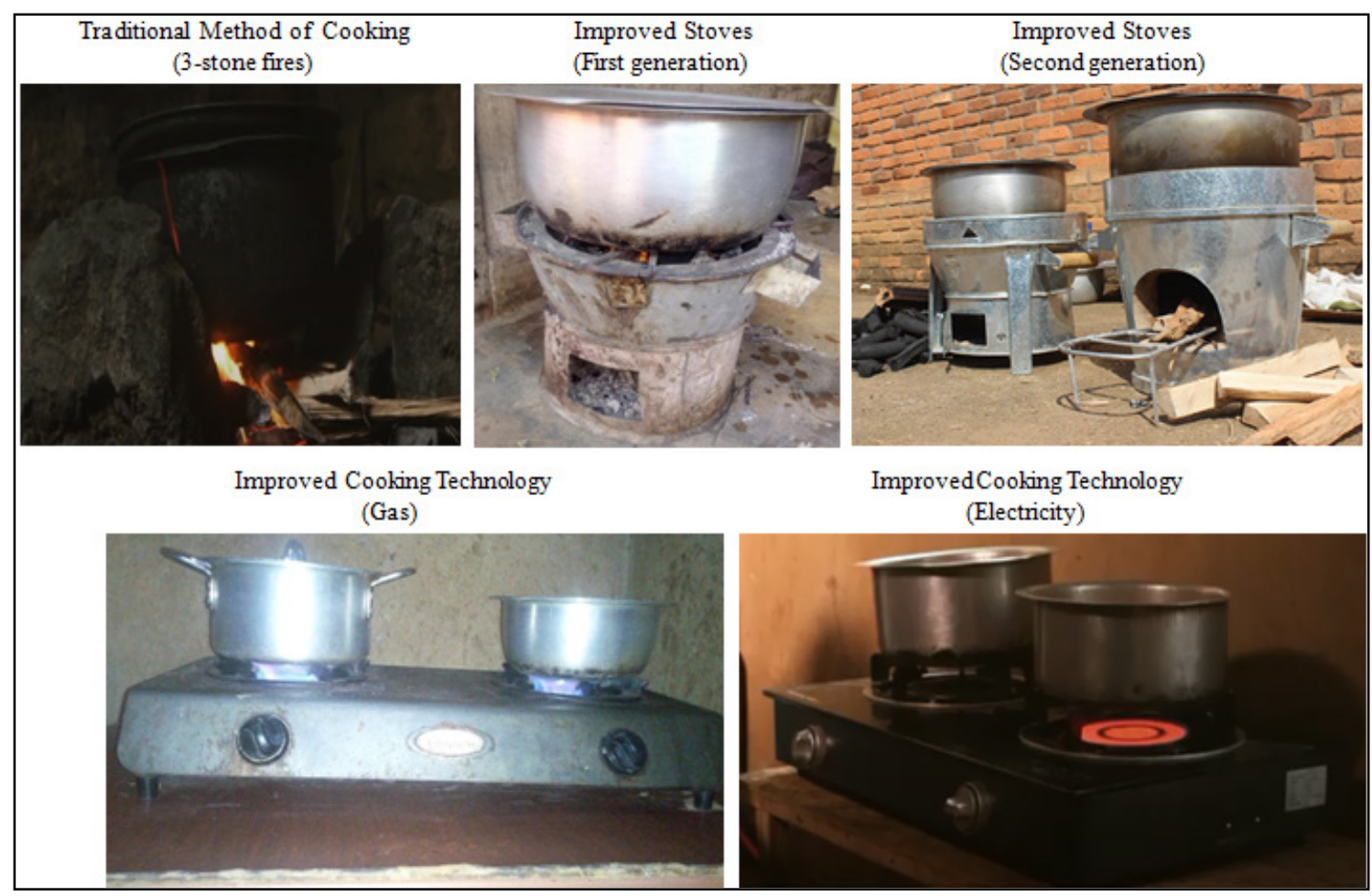

Figure 4. The classification of cooking technologies in Rwanda

\section{Improved Cooking Technologies in Rwanda}

Rwanda Energy Group (REG), in partnership with its stakeholders, is carrying out a countrywide awareness campaign on the use of safe, effective and clean cooking technologies to ensure that Rwanda meets its targets to reduce the use of biomass energies to cook in households. Currently, around 83 percent of Rwandans still use firewood for cooking but by 2024 . Rwanda is targeting to have reduced the figure to 42 percent as shown in table 3 . The performance of a cook stove is characterized by three processes: Heat-transfer efficiency depends primarily on the geometry of the cook stove and the flow of hot gases around the bottom and sides of the pot. Combustion efficiency, by contrast, depends primarily on the temperature in the cook stove and the characteristics of the combustion chamber that affects the circulation of air. Overall thermal efficiency can be raised by improving either combustion efficiency or heat-transfer efficiency [3]. The use of improved cook stoves that are up to three times more efficient than the traditional 3-stone stove and can reduce biomass consumption by anywhere between 68-94\%. The transition from traditional cooking to modern energy cooking solution is shown in figure 4.
As well as the fuel used, the type of stove has a significant impact on the amount of fuel required and the health of households. Most households (66\%) use three-stone cookstoves (the simplest cookstove, made by placing a pot on three stones, which are positioned around a fire) or traditional cooking stoves. These are normally used with firewood. The average household uses around 1.8 tonnes of firewood each year to satisfy its cooking needs with this type of cookstove. The average monthly consumption per household on firewood is RWF 1,930 (\$2.27) [10].

A government program to support the use of improved cooking technologies has run since the 1980s with 30\% household penetration. Private sector led efforts are also distributing cook stoves that are up to three times more efficient than the traditional 3-stone stove and can reduce biomass consumption by anywhere between $68-94 \%$. The consumption of charcoal for cooking can cost up to 36,000 francs per month for a family in Rwanda when one bottle of $24 \mathrm{~kg}$ costing 28,000 francs would be sufficient for the same family and the same period and be less harmful. However, most of the families do not realize that charcoal is more expensive as they buy it in small quantities daily [16]. The different types of stoves and their combustion performance are shown in figure 5 . 


\begin{tabular}{|c|c|c|c|c|}
\hline $\begin{array}{l}\text { Combustion } \\
\text { technologies }\end{array}$ & 3-stone fires & $\begin{array}{l}\text { Improved stoves (first } \\
\text { generation) }\end{array}$ & $\begin{array}{l}\text { Improved stoves } \\
\text { (second generation) }\end{array}$ & $\begin{array}{l}\text { Stoves of high } \\
\text { efficiency }\end{array}$ \\
\hline Efficiency & 8 to $12 \%$ & 20 to $25 \%$ & 25 to $35 \%$ & $>35 \%$ \\
\hline $\begin{array}{l}\text { Particulate matter } \\
\text { per } \mathrm{m}^{3}\end{array}$ & $2,800 \mathrm{ppm}$ & $1,700 \mathrm{ppm}$ & $<1,000 \mathrm{ppm}$ & $<250 \mathrm{ppm}$ \\
\hline Energy type & Thermal energy & Thermal energy & $\begin{array}{l}\text { Thermal energy, } \\
\text { electric energy }\end{array}$ & $\begin{array}{l}\text { Thermal energy, } \\
\text { electric energy, } \\
\text { chemical energy }\end{array}$ \\
\hline Conversion type & Combustion & Combustion & $\begin{array}{l}\text { Combustion, } \\
\text { gasification }\end{array}$ & $\begin{array}{l}\text { Combustion, } \\
\text { gasification, } \\
\text { liquefaction }\end{array}$ \\
\hline
\end{tabular}

Figure 5. Global Alliance for Clean Cook stoves (GACC) tier-based performance standards for cook-stoves [15]

Table 3. Targets for modern cooking technologies uptake by households and Forecast firewood reduction

\begin{tabular}{|c|c|c|c|c|c|c|}
\hline Cooking type & $\begin{array}{c}\text { Year } \\
2018 / 2019\end{array}$ & $\begin{array}{c}\text { Year } \\
2019 / 2020\end{array}$ & $\begin{array}{c}\text { Year } \\
2020 / 2021\end{array}$ & $\begin{array}{c}\text { Year } \\
2021 / 2022\end{array}$ & $\begin{array}{c}\text { Year } \\
2022 / 2023\end{array}$ & $\begin{array}{c}\text { Year } \\
2023 / 2024\end{array}$ \\
\hline Households using firewood & $83 \%$ & $74.80 \%$ & $66.60 \%$ & $58.40 \%$ & $50.20 \%$ & $42.0 \%$ \\
\hline Households using alternative fuel & 542.177 & 835,368 & $1,150,858$ & $1,489,985$ & $1,854,094$ & $2,244,642$ \\
\hline Households moved off firewood & 137,219 & 293,191 & 315,490 & 339,127 & 364,109 & 390,548 \\
\hline
\end{tabular}

\section{Results and Discussions}

\subsection{Environmental Impact Assessment Results}

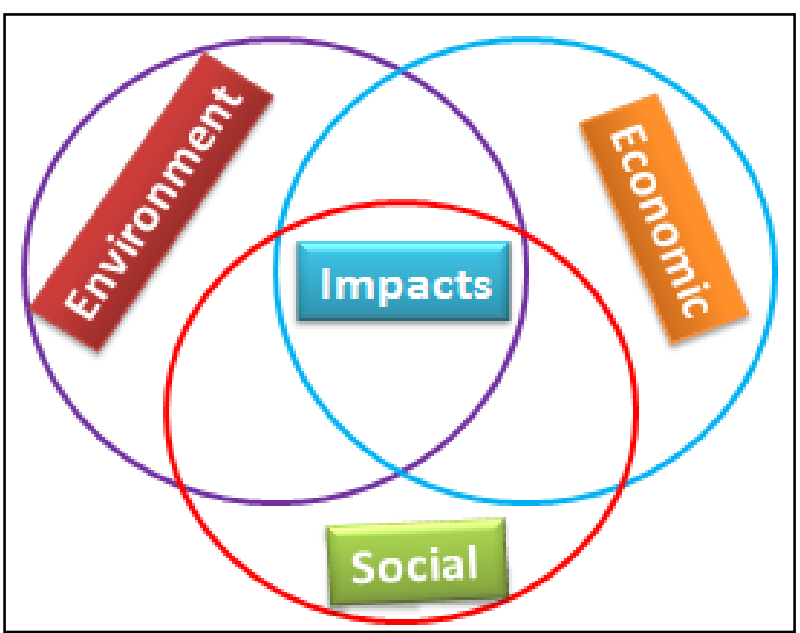

Figure 6. Comparative assessment results of biomass energy

The potential of biomass has not been effectively used in the provision of modern energy for a variety of reasons. One is the failure to exploit the opportunities for transforming wastes from agricultural production and processing into locally produced modern energy. Continued over-dependence on unsustainable wood fuel, biomass residue and other forms of biomass as the primary sources of energy to meet household energy needs has contributed to uncontrolled harvesting of trees and shrubs with negative environmental impacts. Besides, continued consumption of traditional biomass fuels contributes to poor health among users due to excessive products of incomplete combustion and smoke emissions in the poorly ventilated houses common in rural areas [2]. Proper impacts studies are needed to assess the genuine social, environmental and economic benefits of biomass energy source for households are shown in figure 6.

\subsubsection{Environmental Impacts}

As a developing country, Rwanda uses wood and charcoal for cooking and heating fuels. Burning biomass releases carbon dioxide $\left(\mathrm{CO}_{2}\right)$, a greenhouse gas. However, the plants that are the source of biomass for energy capture almost the same amount of $\mathrm{CO}_{2}$ through photosynthesis while growing as is released when biomass is burned which can make biomass a carbon neutral energy source. The environmental impacts of biomass energy in Rwanda are the changes in forest areas, degradation, biodiversity, regeneration, ecosystem services and greenhouse gases, etc.

Beyond the availability of firewood and charcoal, the most significant impact of wood and charcoal cooking is the effects on people's health and the environment in general. According to the ministry of health, more than three million Rwandans suffer from respiratory problems every year, of which 13 percent are caused by air pollution. In 2017 , deaths linked to poor air quality reached 12,000 and over 9,040 deaths out of 12,000 were due to indoor air pollution and 2,960 due to ambient air pollution [12]. The 
use of an alternative or improved cooking technology caused some impacts such as reduction of respiratory illnesses caused by indoor and outdoor air pollution and injuries occurring in unsafe kitchen environments, such as burns from contact with the stove's hot surface, scalds from moving pots from a stove that has raised obstructions along its edges, or cuts through contacts with sharp edges. The environmental impacts and proposed mitigation measures are summarized in table 4 .

\subsubsection{Social Impacts}

Charcoal is often blamed for the destruction of the forests and this is both true and false. In the past, charcoal was one of the factors that contributed to deforestation, although it was not the main factor: land clearing for agriculture, for habitation, and for creating tea plantations contributed more to the destruction of the natural forests than did the demand for charcoal. The rural employment and income opportunities will be lost but also because urban households and low income would have trouble finding cooking fuels. If the rural and urban household continues to cut trees for firewood and timber, etc.., the country risks desertification and that's why everybody should be aware of the consequences and embrace the safe cooking system and also improve environmental protection. Indoor pollution and illness are the health impacts of the use of biomass energy (charcoal, firewood). Many households across rural Rwanda look to forests as a source of income, cutting down trees to supply growing markets for charcoal and timber, however, urged them to embrace sustainable charcoal production to protect the country's forest cover. The protection of our environment must be a high priority to forest conservation while subsidizing households to use alternative energy sources [11]. The use of uncontrolled trees has contributed to deforestation in some parts of the country as shown in figure 7. The changes are meant to reduce the cutting down of trees as well as respiratory diseases that kill an estimated 12,000 people annually.

Table 4. Summary of environmental impacts and proposed mitigation measures

\begin{tabular}{|c|c|c|c|}
\hline Parameters & Impacts (negative and positive) & Mitigation measures & Action and responsible \\
\hline Air pollution & $\begin{array}{l}\text { Biomass contains less than } 0.1 \% \text { of } \\
\text { Sulphur. This problem of } \mathrm{SO}_{2} \text { will } \\
\text { not be there when biomass is } \\
\text { burning }\end{array}$ & \multirow{2}{*}{$\begin{array}{l}\text { If people harvest the wood } \\
\text { faster than trees can grow it } \\
\text { causes deformation. Planting } \\
\text { fast growing trees for fuel } \\
\text { using fuel efficient cooking } \\
\text { stove can help slow } \\
\text { deforestation and improve the } \\
\text { environment }\end{array}$} & $\begin{array}{l}\text { Government of Rwanda through } \\
\text { REMA has to set out a strategy to } \\
\text { reduce reliance on wood and } \\
\text { charcoal. }\end{array}$ \\
\hline Carbon dioxide balance & $\begin{array}{l}\mathrm{CO}_{2} \text { produced when biomass is } \\
\text { burning or when biomass is } \\
\text { converted into gas or liquid fuels } \\
\text { does not disturb } \mathrm{CO}_{2} \text { balance in the } \\
\text { atmosphere. }\end{array}$ & & $\begin{array}{l}\text { The strategies undertaken by the } \\
\text { government to reduce the } \\
\text { dependence on biomass include } \\
\text { encouraging the use of institutional } \\
\text { biogas and liquefied petroleum gas } \\
\text { and ensuring affordable prices }\end{array}$ \\
\hline $\begin{array}{l}\text { Ash from firewood or } \\
\text { charcoal production }\end{array}$ & $\begin{array}{l}\text { Burnt biomass leaves ash which is } \\
\text { rich in plant nutrients mineral }\end{array}$ & It can be used as fertiliser. & Concerned people \\
\hline $\begin{array}{l}\text { Ash from waste biomass } \\
\text { plants }\end{array}$ & $\begin{array}{l}\text { Some landfills use ash that is } \\
\text { considered safe as a cover layer for } \\
\text { the landfills and other used to make } \\
\text { concrete blocks bricks }\end{array}$ & $\begin{array}{l}\text { Separating biomass waste } \\
\text { before burning. }\end{array}$ & Plant managers \\
\hline Ecological conditions & Land becomes green & $\begin{array}{l}\text { Encouraging all urban, rural } \\
\text { and refugee households to use } \\
\text { gas or other improved } \\
\text { cooking technologies. }\end{array}$ & $\begin{array}{l}\text { Local administration authorities and } \\
\text { REMA }\end{array}$ \\
\hline
\end{tabular}

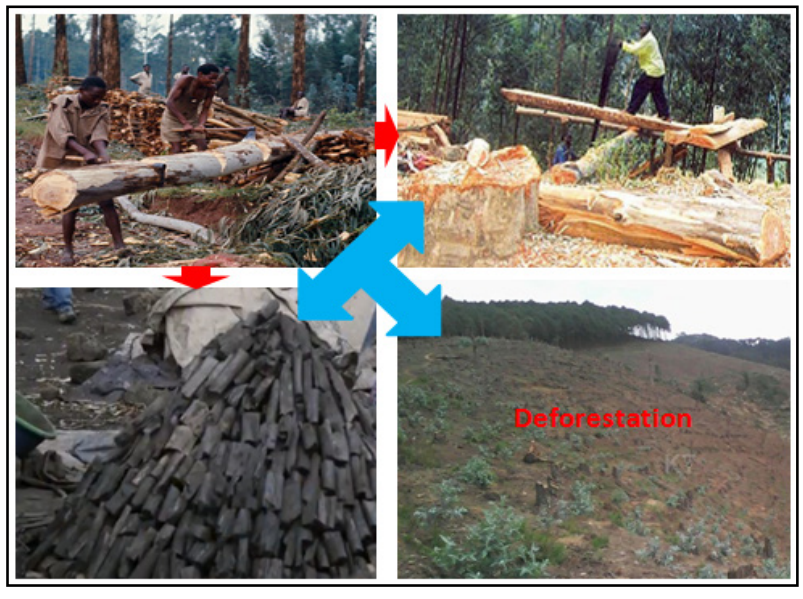

Figure 7. The use of trees in the country

\subsubsection{Economic Impacts}

By displacing the use of biomass (firewood or charcoal) energy sources, biogas and LPG can help to reduce households' energy expenses. The use of biomass energy has potentially serious environmental implications and forests, woodlots are more productively produced and charcoal more efficiently used in countrywide. In this regard, the deforestation is increased as the demand for energy is increasing due to the population increases. The energy policy proposes more efficient production and use of biomass energy by households for encouraging the shift to use of non-biomass modern energy and high efficient biomass technologies by promoting the use of other sources of energy including cooking gas, biogas, pellets and briquettes. To ensure environment protection the, all households in the urban and rural areas are encouraged to use modern gas and stoves for cooking. The distribution of fuel-efficient cookstoves reduces the amount of wood burning in households, which means less harmful smoke, less indoor air pollution, and fewer greenhouse gas emissions. The socio-economic impacts for the community and beneficiaries are the change of income, employment, assets, equity, costs and profits, etc. 


\section{Discussions}

\subsection{The Transition from Cooking with Charcoals to LPG Gas in Kigali}

The transition from cooking on the charcoal to another alternative energy source particularly LPG are still at the beginning with some difficulties, like the cost and cultural habits, but the trend shows that more people, especially in urban areas, are attracted by LPG and are willing to change. The government of Rwanda continuous sensitization campaigns, the population becomes aware of the ecological risk of cooking with wood and charcoal and understands the need to adopt clean fuels for cooking. The ministry of environment is set to ban the use and supply of charcoal in Kigali City as it steps up efforts to protect the environment by reducing the use of wood fuel. The use of charcoal has been cited as the main driver of deforestation and indoor air pollution. And the move could help reduce Rwanda's reliance on wood fuel from 80 percent to 42 percent by 2024. It has realized that many households in Kigali city consume a big percentage of charcoal which is a threat to forests across the country yet they can afford cooking gas.
The government has developed an intuitive dubbed "Pay as You Cook" that will make cooking affordable to the public. The intensive use of charcoal was undermining Rwanda's efforts to achieve 30 percent of national forest cover and protecting forests and the use of cooking gas as a way of saving forests. The master plan suggests that the demand for LPG is set to rise to more than 240,000 tonnes by 2024 , from the current 10,000 tonnes which will also reduce respiratory diseases caused by overreliance on wood fuel [12]. Kigali has the most important woodfuels market in Rwanda and draws its supply from all parts of the country. Since the overall supply/demand balance is negative (assuming medium productivity variant), there is no supply zone for Kigali's demand that can be considered entirely sustainable [14]. Figure 8 provides an outline of the proveniences of the charcoal and, tentatively, of the fuelwood sold in Kigali. How did the people of Kigali react to the government's decision not to use charcoal in cooking and heating? Most likely people think that transitioning to gas in the kitchen will be more expensive and they should be made aware of all the government strategies and tools to help them make a smooth transition.

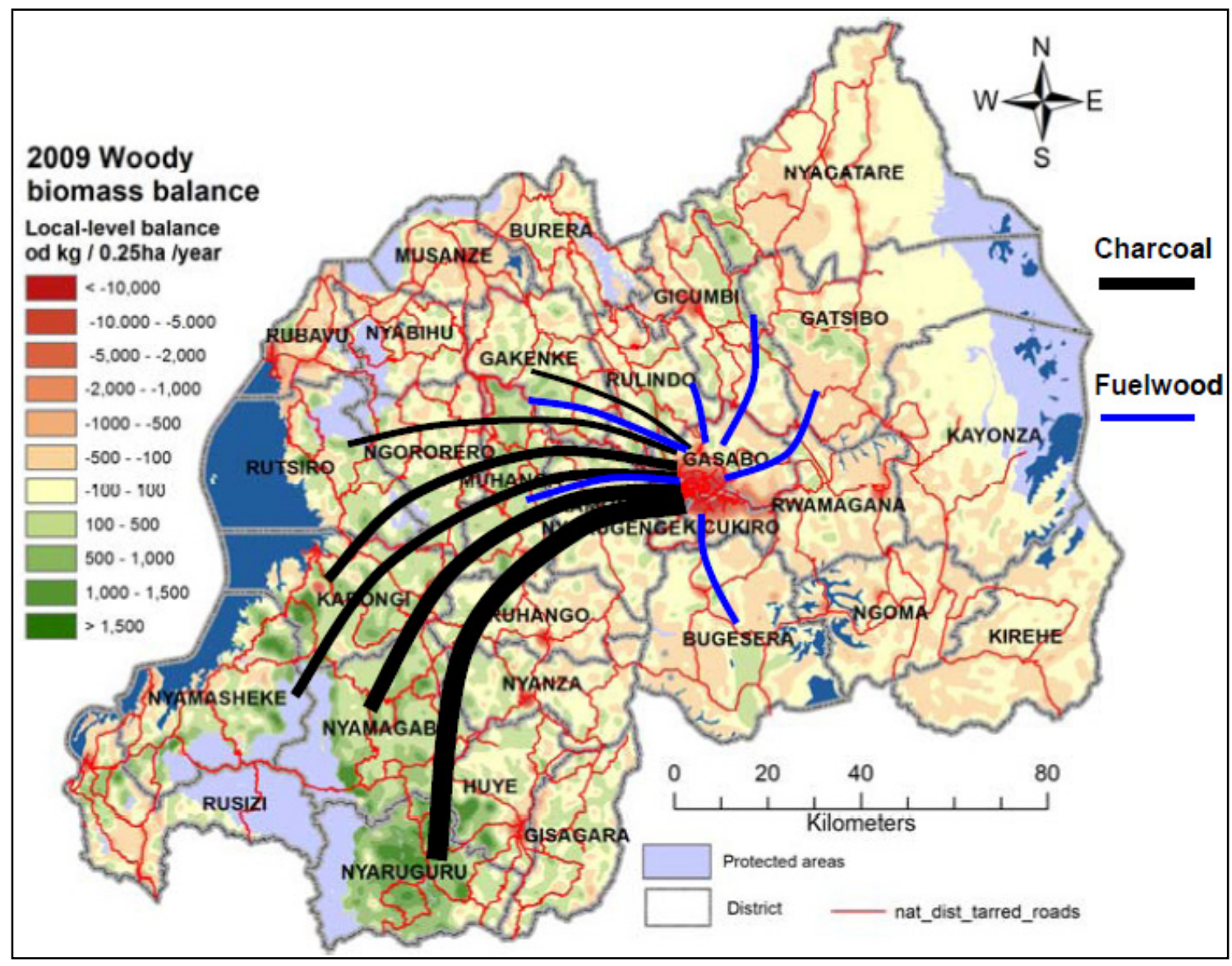

Figure 8. Main proveniences of charcoal and fuelwood supplying in Kigali market [14] 


\subsection{Global Climate Change Impacts}

First, a significant portion of charcoal production wood is unsustainably harvested. Second, emissions during charcoal production are significant compared to those from charcoal burning. Charcoal is produced via pyrolysis, or thermal degradation, of biomass. This partial combustion, in an oxygen-poor environment, results in the formation of products of incomplete combustion (PICs), such as $\mathrm{CH}_{4}$, $\mathrm{CO}$, alkanes, alkenes, oxygenated compounds and particulate matter. In ideal biomass combustion, only $\mathrm{CO}_{2}$ and $\mathrm{H}_{2} \mathrm{O}$ would be formed as shown in figure 9. In practice, however, various amounts of PICs are produced, depending upon operating conditions. An aerosol is a suspension of fine solid particles or liquid droplets in air or another gas [13]. Aerosols can be natural such as fog, mist, dust, forest exudates and geyser steam and can also be anthropogenic such as a particulate air pollutant and smoke.
A non-methane hydrocarbon (NMHC) is emissions from biomass burning and they are important reactive gases in the atmosphere since they provide a sink for hydroxyl radicals and play key roles in the production and destruction of ozone in the troposphere. Energy is needed for cooking as well as for lighting. Most of the energy sources used are biomass-based (fuelwood, charcoal, grass, dung, crop residues) or are extracted from the natural environment (peat, vegetable oils, beeswax). Usually, there are more energy options in urban areas (e.g. LPG and grid-supplied electricity) than in rural areas. A major determinant for the household's decision on fuel use is the price of fuel. Over time, a household may either add to its energy sources or appliances or replace one by another. The determinants of this change, as well as the process of change are reflected in the concept as shown in figure 10.

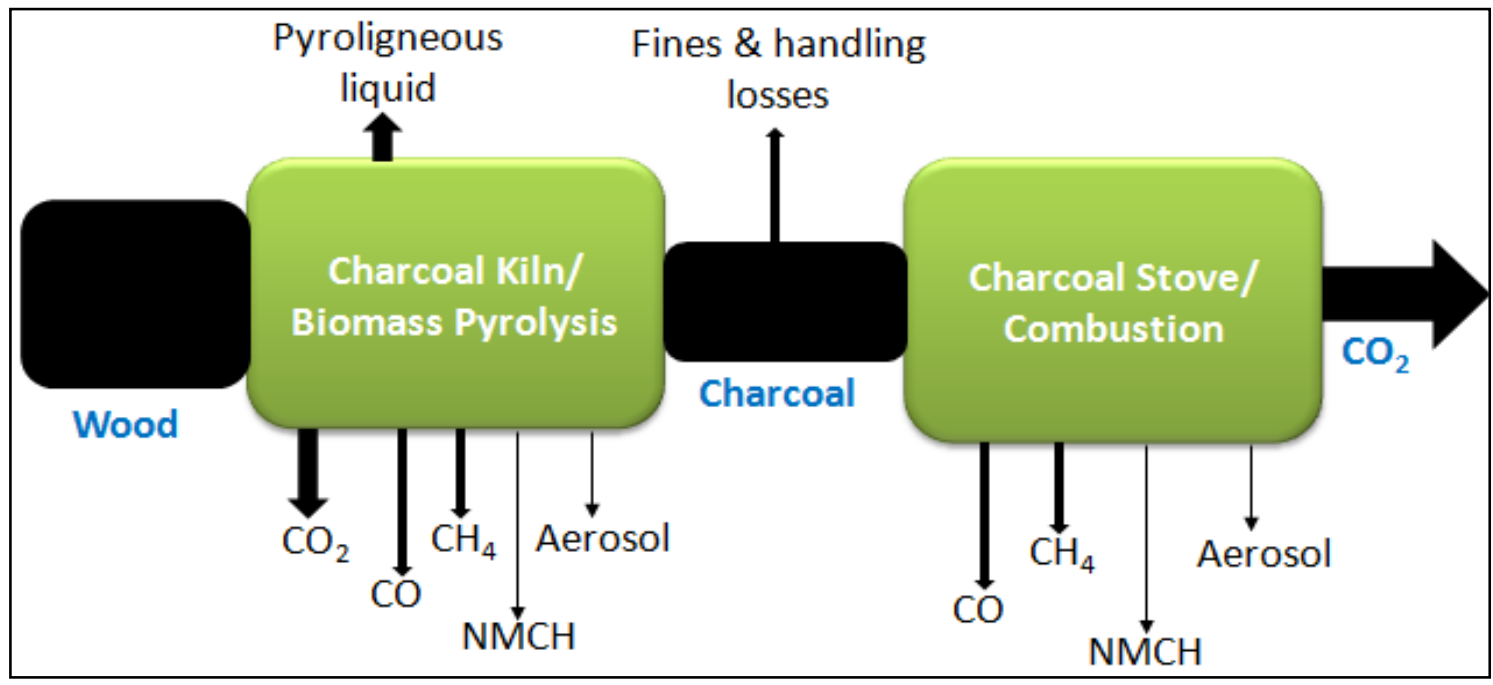

Figure 9. Charcoal production and combustion processes

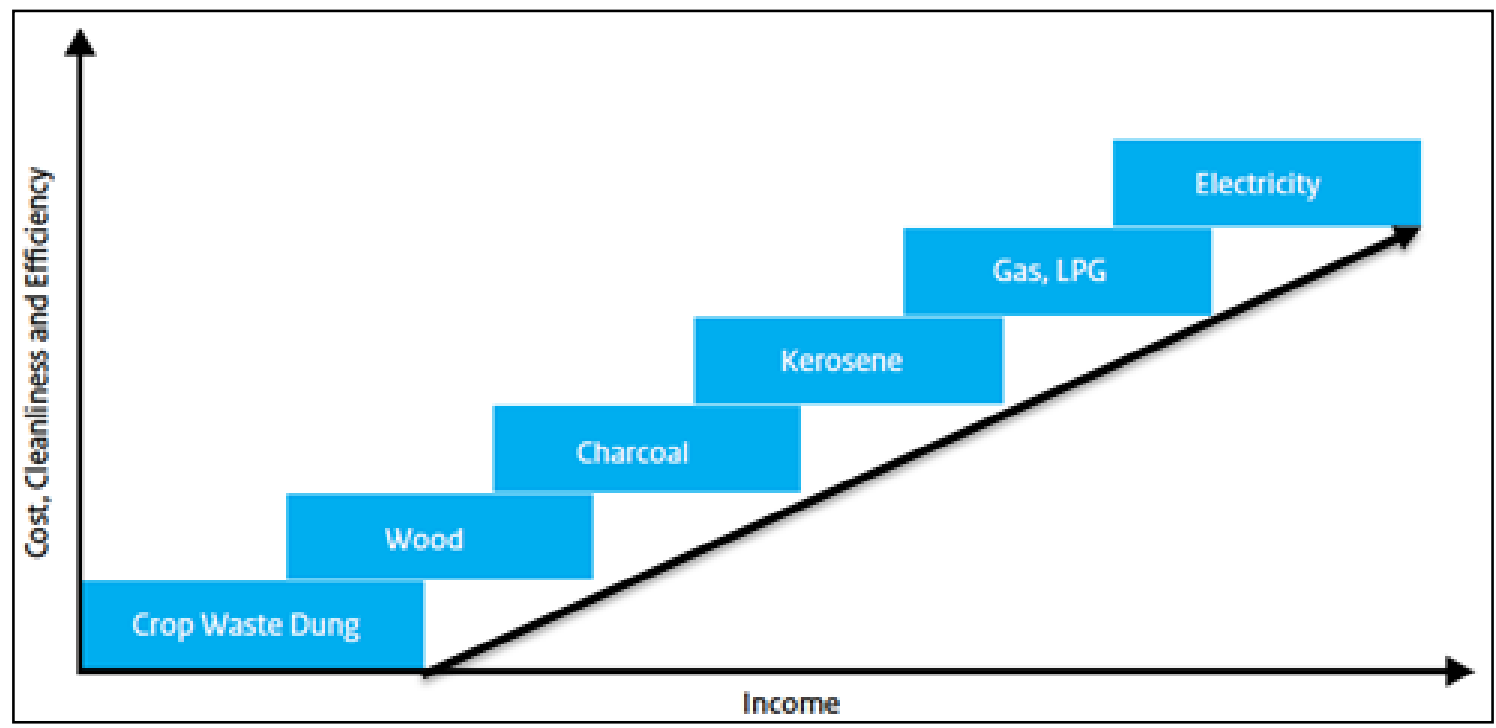

Figure 10. The classic energy used for cooking 


\section{Conclusions}

Rwanda heavily relies on traditional biomass, for instance, wood, charcoal, dung (biogas) with more than 83 percent of households using firewood for daily cooking activities and industries such as tea factories. This is an increase in demand for cooking fuel has exerted immense pressure on forest resource and country aims to reach a potential net reduction in wood use to 5770000tones by 2030 through some mitigation measures, policies, including developing a modern and efficient charcoal value chain and the use of Liquefied Petroleum Gas (LPG) by middle-class households especially in urban areas. The government of Rwanda envisages reducing the reliance on wood fuel for cooking from 83 percent of the households to 42 percent by 2024 . There is a high dependency on inefficient and unclean biomass cooking energy sources has resulted in many adverse such as environment, socio-economic and the health of the population. The government of Rwanda has to put more effort into creating more cooking technologies that use less combustible, like improved stoves, biogas, including making Liquefied Petroleum Gas (LPG) available to people depending on their means of income. As a result of the reduction of the use of woods and save trees harvested before maturity for cooking purposes and protected forest. Historically, wood and charcoal were one of the factors that led to the country's deforestation, but this was not the main factor: land clearing for agriculture, habitation, and for creating tea plantations led more to the destruction of the natural forests than did the demand for charcoal. The uses of briquettes technology to replace fuelwood and any other alternative energy sources have a potential solution to address climate change and deforestation while improving the livelihoods of the community and reducing $\mathrm{CO}_{2}$ emissions. Biogas technology can be used in rural areas as an alternative energy source for cooking. The results show that the biogas generated from agricultural wastes, the process's development was quite slow due to the initial cost of investment required to start production.

The direct causes of deforestation come mainly from the rapidly growing population in rural/urban areas and the economic interests of the country. As population size expands, the needs of food (agricultural expansion), wood extraction (logging or wood harvest for domestic fuel or charcoal), housing, infrastructure expansion such as road construction and urbanization, and energy will increase accordingly. Fuel shortages in rural areas led to wood being used for both heating and cooking. But the traditional rural stoves do have low efficiency in combustion. Moreover, much of the fuel wood used is found in poor quality with the use of wood harvested from the forest. With respect to this phenomenon, it initially contributed to the country's deforestation and economic instability. Rwanda's government must continue the mobilization and awareness for the citizens of Kigali city and the country as a whole has shifted energy supplies from wood to improved cooking technologies and later to Liquefied Petroleum Gas (LPG) or electricity.

\section{REFERENCES}

[1] Xinhua (2017), Rwanda begins campaign to reduce use of firewood, https://www.nation.co.ke/news/africa/, accessed July 21, 2020

[2] Rwanda Energy Group (REG), https://www.reg.rw/what-we-do/biomass/, accessed June 11, 2020.

[3] Venkataraman, C., A. D. Sagar, G. Habib, N. Lam, K. Smith. (2010). "The Indian National Initiative for Advanced Biomass Cookstoves: The Benefits of Clean Combustion." Energy for Sustainable Development 14 (2010) 63-72, DOI: 10.1016/j.esd.2010.04.005

[4] The Republic of Rwanda (2018), National Institute of Statistics of Rwanda (NISR), Rwanda Poverty Profile Report, 2016/17, ISBN: 978-99977-43-39-8

[5] The Republic of Rwanda (2019), Ministry of Infrastructure , Biomass energy strategy, a sustainable path to clean cooking, 2019-2030.

[6] The Republic of Rwanda (2016), Ministry of Infrastructure , Final report and action plan for improvement of charcoal value chain in Rwanda

[7] The Republic of Rwanda (2009), Ministry of Infrastructure, Ministry of Environment and Natural Resources, Background \& Analysis (Biomass Energy Strategy), Volume 2

[8] The Republic of Rwanda (2009), Ministry of Infrastructure, Rwanda - Biomass Energy Strategy, Volume 3 - Rural supply and demand, REFERENCE NO.: 81098569

[9] Ernest Mazimpaka, Woodfuel in Rwanda: Impact on Energy, Poverty, Environment and Policy Instruments analysis, Int. Journal of Renewable Energy Development (IJRED), In Vol 3, No 1 (2014): February 2014 DOI: https://doi.org/10.14710/ijred.3.1.21-32

[10] The Republic of Rwanda (2018), Ministry of Infrastructure, Energy sector strategic plan, 2018/19 - 2023/24,

[11] Xinhua,(2020), Rwanda seeks to reduce charcoal usage to save forests,

http://www.xinhuanet.com//english/2017-04/05/c_1361851

76.htm, accessed May 05, 2020

[12] Michel Nkurunziza (2020), Government to ban charcoal use in Kigali, The New Times, https://www.newtimes.co.rw, accessed June 05,2020

[13] Daniel M. Kammen, Debra J. Lew (2004), Review of Technologies for the Production and Use of Charcoal, National Renewable Energy Laboratory 1617 Cole Boulevard, Golden, CO 80401-3393

[14] Rudi Drigo, Anicet Munyehirwe, Vital Nzabanita and Athanase Munyampundu (2013), As a basis for a Rwanda 
Supply Master Plan for fuelwood and charcoal, Rwanda Natural Resources Authority (RNRA), Ministry of Natural Resources

[15] The World bank report (2019), THIRD RWANDA ENERGY SECTOR DEVELOPMENT POLICY FINANCING, Report No: PGD68

[16] Ladislas Havugimana , The transition from cooking with charcoal to LPG gas in Rwanda (2018-2024), intergovernmental research and policy journal (IRPJ), https://irpj.euclid.int/the-transition-from-cooking-with-char coal-to-lpg-gas-in-rwanda-2018-2024/, accessed June 18, 2020 .

[17] The Republic of Rwanda (2014), Ministry of Infrastructure, Sustainable Energy for All. Rapid Assessment and Gap Analysis, Supported by African Development Bank (AfDB)

[18] Rwanda Energy Group (REG),

https://www.reg.rw/about-us/history/, accessed June 08, 2020. 